\title{
Is there a gender difference in antidiuretic response to desmopressin in children?
}

\author{
Kristian Vinter Juul $^{1 *}$, Sandra Goble ${ }^{1}$, Pauline De Bruyne ${ }^{2}$, Johan Vande Walle ${ }^{3}$, \\ Jens Peter Nørgaard ${ }^{1}$ \\ ${ }^{1}$ Global Scientific Affairs Urology, Ferring International Pharma Science Center, Copenhagen, Denmark \\ ${ }^{2}$ Department of Pediatrics and Medical Genetics, Ghent University, Ghent, Belgium \\ ${ }^{3}$ Pediatric Nephrology Unit, Ghent University Hospital, Ghent, Belgium \\ Email: ${ }^{*}$ kvj@,ferring.com
}

Received 22 March 2013; revised 26 April 2013; accepted 4 May 2013

Copyright (C) 2013 Kristian Vinter Juul et al. This is an open access article distributed under the Creative Commons Attribution License, which permits unrestricted use, distribution, and reproduction in any medium, provided the original work is properly cited.

\begin{abstract}
Women with nocturia are more sensitive to desmopressin, a synthetic arginine vasopressin (AVP) analogue, with significant antidiuretic responses to desmopressin orally disintegrating tablet (ODT) $25 \mu \mathrm{g}$, compared with men who require $58 \mu \mathrm{g}$ to achieve similar responses. In children the current desmopressin dose recommendation to treat primary nocturnal enuresis (PNE) is the same for boys and girls. This post hoc analysis of data from a randomised, doubleblind single-dose study of 84 children with PNE aged 6 - 12 years explored gender differences in sensitivity to desmopressin in children. Following water loading to suppress endogenous AVP, placebo or desmopres$\sin 30,60,120,240,360$ or $480 \mu$ g was administered when urinary production reached $>0.13 \mathrm{~mL} / \mathrm{min} / \mathrm{kg}$. The endpoints of urinary osmolality and duration of urinary-concentrating action (DOA) (above three thresholds: 125, 200 and $400 \mathrm{mOsm} / \mathrm{kg}$ ) were analysed to compare efficacy in boys and girls, in each treatment group. The DOA and urinary osmolality were similar in both genders in the desmopressin $120-480 \mu \mathrm{g}$ groups. Boys receiving desmopressin ODT 30 - $60 \mu \mathrm{g}$ tended to increased urinary osmolality and experienced 1 - 2 hours longer DOA than girls. The same pattern of higher values in boys compared with girls was seen for all measures of urinary osmolality. Conclusion: In a limited sample of pre-pubertal children the antidiuretic response to desmopressin was largely similar between genders, in contrast to findings in adults.
\end{abstract}

Keywords: Desmopressin; Antidiuresis; Gender

"Corresponding author.
Difference; Paediatric; Arginine Vasopressin Receptor 2

\section{INTRODUCTION}

The concept of a gender difference in renal sensitivity to desmopressin has been supported by several studies in adult patients with nocturia. In the double-blind, placebocontrolled NOCTUPUS studies, testing desmopressin tablets $(0.1 \mathrm{mg}, 0.2 \mathrm{mg}$ or $0.4 \mathrm{mg})$ in 144 women [1] and 151 men [2], a $\geq 50 \%$ reduction in nocturnal voids was achieved in $46 \%$ of women and in $34 \%$ of men; women had a $78 \%$ increase in mean first sleep period compared with a $59 \%$ increase in men. In a trial of desmopressin orally disintegrating tablets (ODT; Minirin ${ }^{\circledR}$ Melt), 799 nocturia patients were randomised to placebo or desmopressin ODT $(10,25,50$ or $100 \mu \mathrm{g})$, for one month [3]. Post hoc analyses by gender demonstrated a significantly greater decrease in nocturnal urine volume in women at the lower doses of $10 \mu \mathrm{g}$ and $25 \mu \mathrm{g}$ compared with men $\left(\mathrm{ED}_{50} \quad 16.1 \mu \mathrm{g}\right.$ vs. $\left.43.2 \mu \mathrm{g}\right)$, suggesting significantly higher sensitivity to desmopressin in women [4]. A recent pharmacodynamic (PD) study of desmopressin in water-loaded Japanese patients with nocturia found that male patients required $58 \mu \mathrm{g}$ desmopressin ODT to achieve a similar duration of antidiuretic action as achieved by female patients receiving desmopressin 25 $\mu \mathrm{g}$ [5]. A recent meta-analysis of data from nocturia trials with desmopressin demonstrated a durable gender difference in sensitivity to desmopressin in favour of females. Greater efficacy was observed with desmopressin ODT $25 \mu \mathrm{g}$ in females compared with males, which endured over the long term (one year or more) [6]. Two physiological mechanisms behind this gender difference in renal sensitivity to desmopressin have been suggested, including the genetic X-inactivation mechanism and the 
endogenous regulation of AVP by sex hormones [4].

In children with monosymptomatic nocturnal enuresis (MNE), current desmopressin ODT dosing recommendations $(60-240 \mu \mathrm{g})$ are the same for boys and girls. However, there is substantial evidence that absence of a nocturnal increase in AVP release is a contributing factor for nocturnal polyuria and enuresis [7], and that more boys than girls are affected by the condition. In a large epidemiological study, $16.1 \%$ of children aged five years were reported to have PNE, with double the proportion of boys compared with girls, $20.7 \%$ vs. $10.8 \%$, respectively, reported to have PNE [8]. Several research papers have confirmed that females have significantly lower basal AVP levels compared to males, both in children [9] and in young adults [10-12]. Since no difference in urine volume or osmolarity was found in these studies, it is reasonable to assume that women and girls concentrate urine at lower plasma AVP levels than men and boys.

Emerging evidence supports the hypothesis that females have an increased sensitivity to both AVP and to the AVP receptor 2 (V2 receptor) specific agonist, desmopressin. In adult patients with nocturia, gender-specific dosing of desmopressin provides the clinical advantage of minimising the risk of hyponatraemia while still achieving a meaningful patient benefit in reducing nocturnal voids [13]. However, there is a lack of evidence of gender differences in children in response to V2 receptor stimulation, and no paediatric gender-specific dose recommendations have been suggested.

Thus, the purpose of this paper is to explore possible gender differences in children by quantifying the urineconcentrating effects of desmopressin at different doselevels using a gender-stratified analysis of a previously reported clinical study in children. While we recognise that a post hoc analysis is not as powerful as a primary analysis, ethical considerations led us to explore relevant data already collected prior to setting up a new interventional study in children. The current analysis also supports power calculations for any prospective study protocols in a paediatric population examining gender difference in response to V2 receptor stimulation.

\section{PATIENTS AND METHODS}

Clinical data were derived from a PD double-blind, randomised, parallel-group study in children and adolescents with primary MNE [14].

\subsection{Patients}

The study was conducted in 84 children and adolescents. Boys or girls aged 6 - 13 years and of normal body weight (body mass index [BMI] $14-25 \mathrm{~kg} / \mathrm{m}^{2}$ ) were eligible for the study if primary MNE had been demon- strated during a run-in period. All patients were otherwise healthy. Exclusion criteria included evidence of organic urological disease, diurnal urinary incontinence, diabetes insipidus, ongoing urinary tract infection or any clinically significant disease likely to interfere with the evaluation; use of antibiotics, diuretics or any drug affecting urinary concentration; use of any therapy (pharmacological or conditioning), including desmopressin for PNE within 30 days of study entry; and abnormalities or disease of the oral cavity that might affect the release or absorption of the orally dispersible formulation.

\subsection{Study Design}

The study design and the clinical and safety results of this study have been reported in detail elsewhere [14]. Briefly, eligible patients were randomised to either placebo or one of six single doses of 30, 60, 120, 240, 360 or $480 \mu \mathrm{g}$ desmopressin. All patients were water-loaded before dosing to suppress endogenous AVP. Desmopressin or placebo were administered when urinary production reached $>0.13 \mathrm{~mL} / \mathrm{min} / \mathrm{kg}$. Urinary volume, osmolality and duration of urinary-concentrating action (DOA) (above three threshold levels: 125, 200 and 400 $\mathrm{mOsm} / \mathrm{kg}$ ) were measured.

The study was approved by the institutional review board or ethics committee for each site, the Declaration of Helsinki was followed, and informed consent obtained from all patients and healthy volunteers. All data used are based on the ODT formulation of desmopressin.

\subsubsection{Software}

Statistical evaluation was performed using SAS (v9.2).

\subsubsection{Endpoints and Analysis}

The mean, maximum and area under curve (AUC) of urinary osmolality and the DOA (above three threshold levels: 125,200 and $400 \mathrm{mOsm} / \mathrm{kg}$ ) were compared between genders, for each treatment group, unless $n \leq 1$. For DOA analysis, patients with urine osmolality above threshold level according to these definitions, at the end of the measurement period, were censored at the time their overhydration procedure stopped. Plots of the distributions of time-adjusted AUC of osmolality, the AUC of urinary osmolality for ten hours following desmopressin administration and maximum urinary osmolality were produced.

Due to the limited sample size and skewed gender distribution of PNE (the ratio of boys to girls was 3.2:1), no formal statistical testing was done. Any comparison between the two genders is therefore based on descriptive statistics, supplemented by visual evaluation of the graphs. 


\section{RESULTS}

\subsection{Demographics}

There were no major demographic differences in the baseline characteristics of patients in each of the treatment groups (Table 1). Since no prospective gender stratification was planned, and PNE is more prevalent in boys, the study had a skewed gender distribution with more boys than girls in all treatment groups. The majority of patients were of a pre-pubertal age, with a mean age of nine years (range 6 - 13). No patient was overweight according to the definition of BMI above $25 \mathrm{~kg} / \mathrm{m}^{2}$.

\subsection{Duration of Urinary-Concentrating Action above Three Threshold Levels: 125, 200 and $400 \mathrm{mOsm} / \mathrm{kg}$}

In the higher dose groups, no clear difference between the genders in DOA was seen, although direct compari- son between genders in the 120 and $240 \mu \mathrm{g}$ dose groups was prevented as only one girl was assigned to each of those dose groups. Only in the highest dose group (desmopressin $480 \mu \mathrm{g}$ ) was a modestly longer mean DOA observed in girls compared with boys. In the low-dose groups (desmopressin 30 and $60 \mu \mathrm{g}$ ) boys had $1.6-2$ hours longer mean DOA compared with girls for all three threshold levels of osmolality (Table 2).

Examining the two lowest dose groups together by gender produced a DOA distribution curve for boys that was rightward shifted compared with the DOA distribution curve for girls, indicating a modest increase in mean DOA of desmopressin in boys, due in part to more outliers amongst the boys with a DOA of around 10 - 12 hours (Figure 1).

\subsection{Mean, Maximum and AUC of Urinary Osmolality}

In the higher dose groups all three measurements of uri-

Table 1. Demographic characteristics.

\begin{tabular}{|c|c|c|c|c|c|c|}
\hline \multirow{2}{*}{ Dose $(\mu \mathrm{g})$} & \multicolumn{2}{|c|}{$\mathrm{n}$} & \multicolumn{2}{|c|}{ Age (years) } & \multicolumn{2}{|c|}{ BMI $\left(\mathrm{kg} / \mathrm{m}^{2}\right)$} \\
\hline & Female & Male & Mean & SD & Mean & SD \\
\hline Placebo & 2 & 10 & 9.3 & 2.1 & 18.7 & 3.5 \\
\hline 30 & 2 & 10 & 8.0 & 1.4 & 16.1 & 1.2 \\
\hline 60 & 5 & 7 & 9.4 & 2.1 & 17.7 & 3.1 \\
\hline 120 & 1 & 10 & 8.7 & 2.0 & 16.6 & 2.8 \\
\hline 240 & 1 & 11 & 8.4 & 1.7 & 17.0 & 2.0 \\
\hline 360 & 4 & 9 & 9.1 & 2.4 & 17.9 & 2.9 \\
\hline 480 & 5 & 7 & 9.1 & 1.9 & 16.4 & 1.5 \\
\hline
\end{tabular}

BMI, body mass index.

Table 2. Mean duration of urinary-concentrating action in hours stratified by gender.

\begin{tabular}{|c|c|c|c|c|c|c|c|c|c|}
\hline & & & Placebo & $30 \mu \mathrm{g}$ & $60 \mu \mathrm{g}$ & $120 \mu \mathrm{g}$ & $240 \mu \mathrm{g}$ & $360 \mu \mathrm{g}$ & $480 \mu \mathrm{g}$ \\
\hline \multirow{5}{*}{ DOA $125 \mathrm{mOsm} / \mathrm{kg}$} & \multirow{2}{*}{$\mathrm{n}\left(\right.$ censored $\left.^{\mathrm{a}}\right)$} & q & $2(0)$ & $2(0)$ & $5(0)$ & $1(0)$ & $1(1)$ & $4(3)$ & $5(3)$ \\
\hline & & $\widehat{\jmath}$ & $10(2)$ & $10(3)$ & $7(2)$ & $10(4)$ & $11(6)$ & $9(7)$ & $7(4)$ \\
\hline & \multirow{2}{*}{ Mean (SD) } & q & $0.0(0.0)$ & $2.0(1.6)$ & $4.9(2.2)$ & $7.6^{\mathrm{b}}$ & $11.6^{\mathrm{b}}$ & $9.4(1.1)$ & $11.0(0.8)$ \\
\hline & & $\hat{0}$ & $0.7(1.4)$ & $3.9(2.1)$ & $6.5(2.5)$ & $8.2(2.0)$ & $9.5(1.9)$ & $10.6(0.7)$ & $10.2(0.8)$ \\
\hline & Gender difference & $\widehat{\delta}-q$ & 0.7 & 1.9 & 1.6 & c & c & 1.2 & -0.8 \\
\hline \multirow{5}{*}{ DOA $200 \mathrm{mOsm} / \mathrm{kg}$} & \multirow{2}{*}{$\mathrm{n}\left(\right.$ censored $\left.^{\mathrm{a}}\right)$} & q & $2(0)$ & $2(0)$ & $5(0)$ & $1(0)$ & $1(1)$ & $4(1)$ & $5(3)$ \\
\hline & & $\hat{0}$ & $10(0)$ & $10(0)$ & $7(0)$ & $10(3)$ & $11(4)$ & $9(4)$ & $7(3)$ \\
\hline & \multirow{2}{*}{ Mean (SD) } & q & $0.0(0.0)$ & $0.9(1.3)$ & $3.8(1.7)$ & $7.2^{\mathrm{b}}$ & $9.8^{\mathrm{b}}$ & $8.8(0.8)$ & $9.8(1.2)$ \\
\hline & & $\hat{\delta}$ & $0.1(0.2)$ & $2.7(1.7)$ & $6.1(2.9)$ & $7.5(2.2)$ & $8.9(1.8)$ & $9.5(1.8)$ & $9.7(1.3)$ \\
\hline & Gender difference & $\delta-q$ & 0.1 & 1.8 & 2.3 & c & $\mathrm{c}$ & 0.7 & -0.1 \\
\hline \multirow{5}{*}{ DOA $400 \mathrm{mOsm} / \mathrm{kg}$} & \multirow{2}{*}{$\mathrm{n}\left(\right.$ censored $\left.^{\mathrm{a}}\right)$} & q & $2(0)$ & $2(0)$ & $5(0)$ & $1(0)$ & $1(1)$ & $4(0)$ & $5(2)$ \\
\hline & & $\widehat{0}$ & $10(1)$ & $10(0)$ & $7(0)$ & $10(2)$ & $11(2)$ & $9(4)$ & $7(2)$ \\
\hline & \multirow{2}{*}{ Mean (SD) } & q & $0.0(0.0)$ & $0.0(0.0)$ & $2.9(1.6)$ & $3.5^{\mathrm{b}}$ & $9.8^{\mathrm{b}}$ & $8.0(1.3)$ & $8.9(1.8)$ \\
\hline & & $\hat{0}$ & $0.0(0.0)$ & $1.6(1.6)$ & $4.7(3.0)$ & $6.1(2.3)$ & $8.1(2.3)$ & $8.6(2.0)$ & $8.5(1.2)$ \\
\hline & Gender difference & $\hat{\sigma}-q$ & 0 & 1.6 & 1.8 & c & c & 0.6 & -0.4 \\
\hline
\end{tabular}

${ }^{a}$ Patients with osmolality above threshold level at the time their overhydration procedure stopped were censored; ${ }^{\mathrm{b}} \mathrm{SD}$ not calculated as $\mathrm{n}=1$; ${ }^{\mathrm{c}}$ Estimates not calculated as $\mathrm{n} \leq 1$. OA, duration of urinary-concentrating action; $\mathrm{SD}$, standard deviation. 


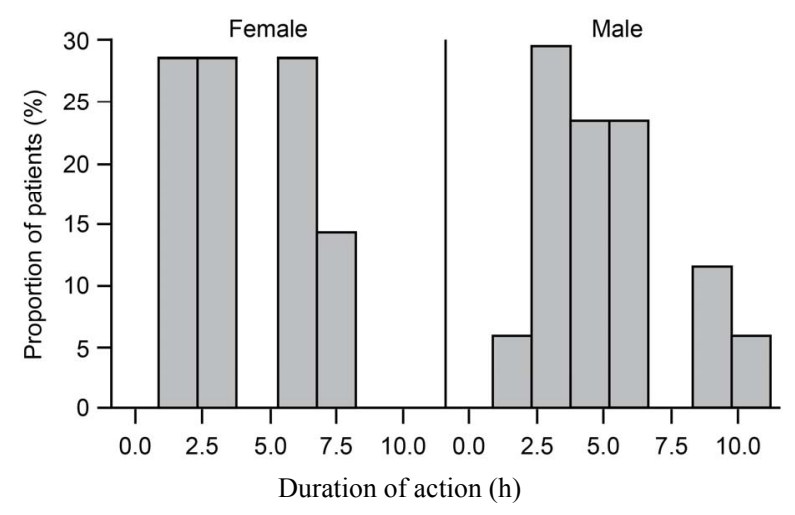

(a)

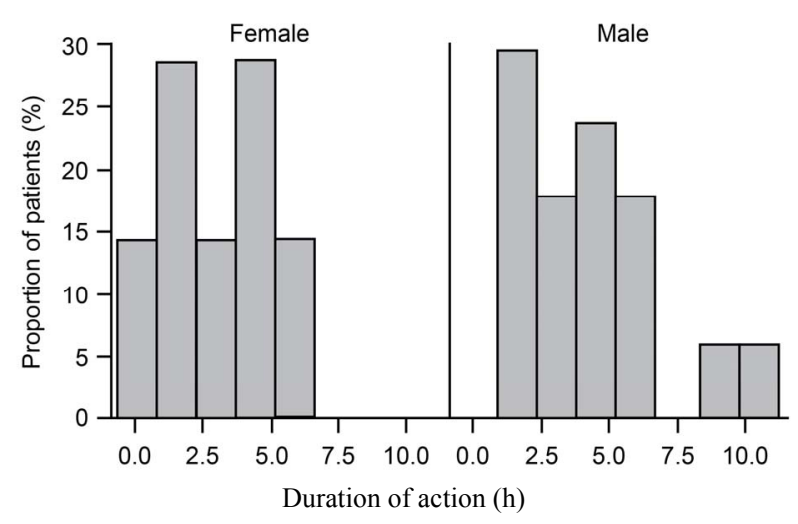

(b)

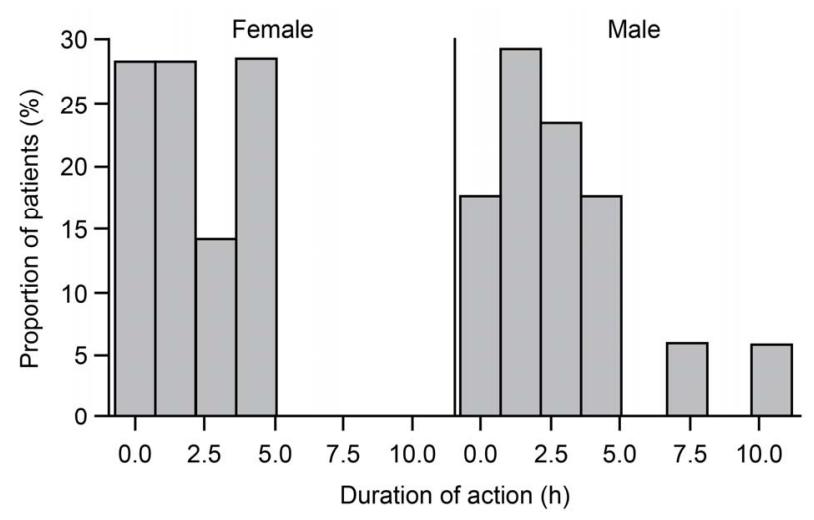

(c)

Figure 1. Distribution of duration of urine-concentrating action with urine osmolality above (a) $125 \mathrm{mOsm} / \mathrm{kg}$, (b) $200 \mathrm{mOsm} / \mathrm{kg}$ and (c) $400 \mathrm{mOSm} / \mathrm{kg}$ in female and male patients following desmopressin $30 \mu \mathrm{g}$ or $60 \mu \mathrm{g}$.

nary osmolality were similar in both boys and girls. Girls did not have a numerically higher mean, maximum or AUC of urinary osmolality following desmopressin administration compared with boys in any dose groups with sufficient sample size (Table 3). In the low-dose groups (desmopressin 30 and $60 \mu \mathrm{g}$ ), boys tended to demonstrate a slightly greater PD response in terms of average, maximum and AUC of urinary osmolality compared with girls.
Plots of the distributions of time-adjusted AUC of osmolality, the AUC of urinary osmolality for ten hours following desmopressin administration and maximum urinary osmolality indicate that across all desmopressin doses tested boys had a slightly longer and more pronounced magnitude of antidiuretic response (Figure 2).

\section{DISCUSSION}

The small sample size and skewed gender distribution in this study prohibit a direct statistical comparison between genders. However, based on descriptive statistics, this post hoc analysis found no clear difference between the genders in either duration or magnitude of desmopressin antidiuretic action in most dose groups.

The most likely explanation for lack of a clear gender difference in children is that for most of the doses used in this study the upper asymptote of the dose-response curve for urine osmolality was already reached. In adults the desmopressin ODT $\mathrm{ED}_{50}$ for reduction in urine volume has been estimated to be $43.2 \mu \mathrm{g}$ and $16.1 \mu \mathrm{g}$ in men and women, respectively, using a maximal response $\left(\mathrm{E}_{\max }\right)$ dose-response model with weight-adjusted dose (dose/weight) and a linear placebo effect [4]. The analysis estimated the dose sensitivity to desmopressin ODT for women relative to men is 2.7 (95\% confidence interval 1.3 - 8.1) [4]. Taking into account the mean body weight of approximately $28 \mathrm{~kg}$ in this study, the likely exposure to desmopressin would be proportionally 2 - 3 times higher in children compared to adults [15]. Assuming linear extrapolation of desmopressin efficacy between adults and children, desmopressin $\mathrm{ED}_{50}$ values in children are likely to be approximately half the magnitude of $\mathrm{ED}_{50}$ values in adults. However, the desmopressin $\mathrm{ED}_{50}$ values for reduction in nocturnal urine volume estimated for adults were derived in patients with nocturia who had not been water-loaded and this study reports urine osmolality and DOA in water-loaded children following desmopressin administration. Nevertheless these data indicate that any future study exploring gender differences in the response to desmopressin ODT in children should include lower doses. We suggest that desmopressin ODT $10 \mu \mathrm{g}$ or a bioequivalent dose in other suitable formulations would be a suitable starting point.

Despite the ambiguity due to the skewed gender distribution, with more boys than girls, in the low-dose desmopressin ODT 30 and $60 \mu \mathrm{g}$ groups, boys had a 1 2 hours longer DOA compared with girls for all three threshold levels. A similar pattern was seen for mean, maximum and AUC of urinary osmolality, with boys receiving desmopressin ODT 30 and $60 \mu \mathrm{g}$ demonstrating higher values compared with girls. Although such a finding is contradictory to the expectation of greater female renal sensitivity to desmopressin, several studies 
Table 3. Average, maximum and AUC of urinary osmolality stratified by gender.

\begin{tabular}{|c|c|c|c|c|c|c|c|c|c|}
\hline & & & Placebo & $30 \mu \mathrm{g}$ & $60 \mu \mathrm{g}$ & $120 \mu \mathrm{g}$ & $240 \mu \mathrm{g}$ & $360 \mu \mathrm{g}$ & $480 \mu \mathrm{g}$ \\
\hline \multirow{2}{*}{$\mathrm{n}$} & & q & 2 & 2 & 5 & 1 & 1 & 4 & 5 \\
\hline & & $\hat{0}$ & 10 & 10 & 7 & 10 & 11 & 9 & 7 \\
\hline \multirow{3}{*}{$\begin{array}{l}\text { Average osmolality during } \\
\text { action }(\mathrm{mOsm} / \mathrm{kg})\end{array}$} & \multirow{2}{*}{ Mean (SD) } & 우 & 37.2 & 136.5 & 381.2 & 569.3 & 844 & 670.2 & 621.9 \\
\hline & & $\pi$ & 51.9 & 305.6 & 524.4 & 576.8 & 656.8 & 684.1 & 665.5 \\
\hline & Gender difference & $\sigma^{\lambda}-q$ & 14.7 & 169.1 & 143.2 & a & a & 13.9 & 43.6 \\
\hline \multirow{3}{*}{$\begin{array}{l}\text { Maximum osmolality during } \\
\text { action }(\mathrm{mOsm} / \mathrm{kg})\end{array}$} & \multirow[b]{2}{*}{ Mean (SD) } & 우 & 83.5 & 263 & 777.2 & 935 & 1049 & 976.8 & 891.8 \\
\hline & & $\sigma^{\pi}$ & 179.7 & 565.2 & 823.7 & 894.9 & 948.37 & 931.1 & 978.7 \\
\hline & Gender difference & $\widehat{o}-q$ & 96.2 & 302.2 & 46.5 & a & a & -45.7 & 86.9 \\
\hline \multirow{3}{*}{$\begin{array}{l}\text { AUC of osmolality } 0 \text { - } 10 \\
\text { hours }(\mathrm{mOsm} / \mathrm{kg})\end{array}$} & \multirow{2}{*}{ Mean (SD) } & q & 278.1 & 775.5 & 3047.3 & 4844.7 & 8301 & 7079.3 & 6425.5 \\
\hline & & $\pi$ & 430.5 & 1932.6 & 4152 & 5352.2 & 6609.3 & 7085.2 & 6455.8 \\
\hline & Gender difference & $\hat{o}-q$ & 152.4 & 1157.1 & 1104.7 & a & a & 5.9 & 30.3 \\
\hline
\end{tabular}

${ }^{\mathrm{a}}$ Estimates not calculated as $\mathrm{n} \leq 1$. AUC, area under the curve; SD, standard deviation.

have demonstrated greater male sensitivity to AVP in young rats [16-18]. One study comparing the renal sensitivity to AVP and density of V2 receptors in young female and male rats (aged 2 - 3 months) found that the young male rats had significantly greater sensitivity to AVP infusion and also significantly greater density of V2 receptors than young female rats [19]. However, a similar study in adult rats found the opposite resultfemale rats expressed significantly more V2 receptor messenger RNA and protein in the kidney than male rats, resulting in a greater sensitivity to V2 receptor agonist administration [20]. Thus, as there are no obvious reasons for the contradictory findings in these rat studies other than the different ages and life-stages of the animals, it suggests that sensitivity to $\mathrm{V} 2$ receptor stimulation is greater in juvenile male individuals, and this inverts to greater female sensitivity with sexual maturity and the influence of oestrogen, known to influence osmoregulation [21], and other sex hormones. Some preclinical studies have suggested that escape from $\mathrm{X}$ inactivation may alter with developmental stages or ageing, providing a possible mechanism for increased female V2R expression with age [22,23].

A gender difference in prevalence of MNE has been shown, with twice as many boys as girls affected by the condition [7]. Furthermore, the normal circadian increase in nocturnal AVP levels is absent in younger patients with enuresis [24]. However, it has not been reported whether puberty and increased levels of endogenous sex hormones increase AVP sensitivity to a larger degree in girls compared with boys. If our finding of no gender difference in response to $\mathrm{V} 2$ receptor stimulation in the paediatric population can be confirmed in a prospective study using lower doses than in our study, this will support the hypothesis that we proposed previously [4]; a gender difference in sensitivity to desmopressin is absent in children since sex hormones are at low levels prior to puberty.

Another possibility for lack of gender difference in children is the recently discovered age-dependent skewing of X chromosome inactivation [25]. While in general young females have a mosaic of cells with either the maternal or the paternal $\mathrm{X}$ chromosome inactivated with a 50:50 distribution, a deviation from this balanced expression may occur with ageing [25]. This may clinically manifest as late-onset X-linked disorders. The AVPR2 gene has known gain and loss of function mutations, leading to syndrome of inappropriate antidiuresis and nephrogenic diabetes insipidus (NDI), respectively [26]. A case of transient NDI associated with decreased V2 receptor expression has been reported in a 55-year-old woman following surgery [27]. However, it remains to be shown if the AVPR2 gene located at xq-28 is subject to late-onset skewing of inactivation, how common such skewing might be and whether other mutations may contribute to V2 receptor expression differences.

Comparative pharmacokinetic (PK)/PD studies of desmopressin have only been performed in a paediatric population by Fjellestad-Paulsen et al. and no gender differences were reported [28]. As in our study, the study populations were predominantly male, and sample sizes were too small to allow gender stratification.

Further research is therefore needed to explore potential gender differences in response to desmopressin in a prospective setting, including sufficient paediatric patients of both genders to allow for a stratified analysis. The current analysis supports power calculations for any such prospective study protocols in a paediatric population on gender difference in response to V2 receptor stimulation. Furthermore, to reduce variation in PD endpoints due to $\mathrm{PK}$ variation, we recommend such a study to be conducted by intravenous infusion of desmopressin. 


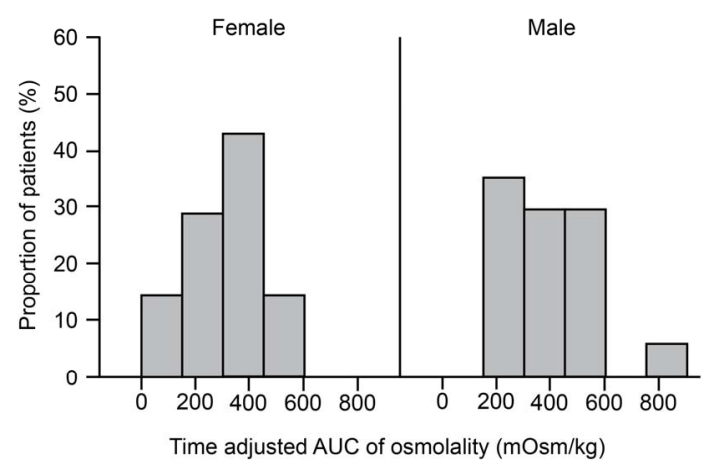

(a)

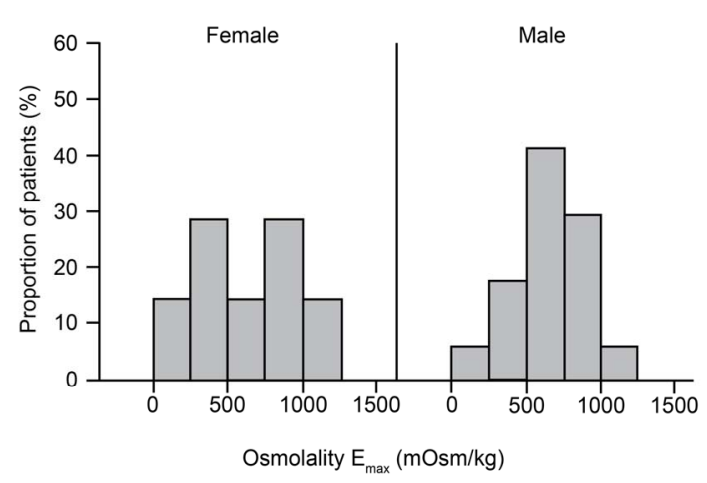

(b)

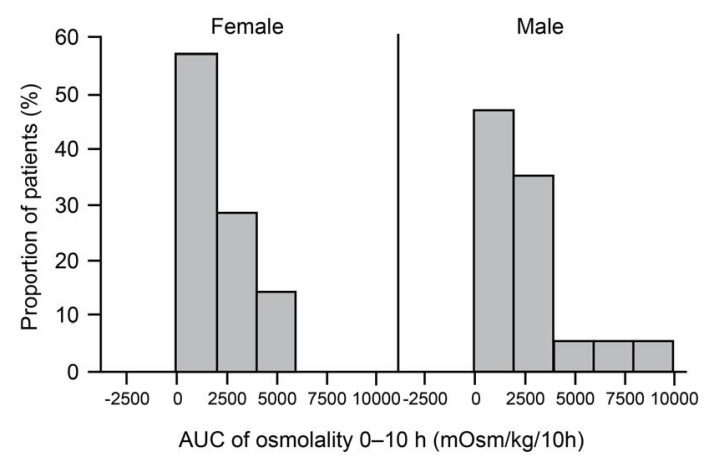

(c)

Figure 2. Distribution of urine osmolality reported as time adjusted AUC, (b) $\mathrm{E}_{\max }$ and (c) AUC over 0 - 10 hours in female and male patients following desmopressin $30-480 \mu \mathrm{g}$. AUC, area under the curve.

A previous study designed to investigate gender differences in desmopressin response in young adults used a bolus injection [29], which does not mimic steady state conditions, but only briefly saturates the V2 receptors. Therefore, we suggest a more suitable approach is to infuse continuously a low dose of desmopressin intravenously (to reach similar concentrations to those achieved using desmopressin ODT $10 \mu \mathrm{g}$ ) until steady state is reached and then gradually increase the dose.

\section{ACKNOWLEDGMENTS}

The authors gratefully acknowledge all the patients and clinical inves- tigators who participated in this trial.

Editorial assistance was provided by Dr Kerry af Forselles, Apothe-

Com ScopeMedical Ltd, funded by Ferring Pharmaceuticals.

\section{CONFLICT OF INTEREST/DISCLOSURE}

Kristian Vinter Juul, Sandra Goble and Jens Peter Nørgaard are employees of Ferring Pharmaceuticals.

Johan Vande Walle has acted as a safety board adviser for Ferring International.

\section{REFERENCES}

[1] Lose, G., Lalos, O., Freeman, R.M. and van Kerrebroeck, P. (2003) Efficacy of desmopressin (Minirin) in the treatment of nocturia: A double-blind placebo-controlled study in women. American Journal of Obstetrics \& Gynecology, 189, 1106-1113. doi:10.1067/S0002-9378(03)00593-3

[2] Mattiasson, A., Abrams, P., van Kerrebroeck, P., Walter, S. and Weiss, J. (2002) Efficacy of desmopressin in the treatment of nocturia: A double-blind placebo-controlled study in men. BJU International, 89, 855-862. doi:10.1046/i.1464-410X.2002.02791.x

[3] Weiss, J.P., Zinner, N.R., Klein, B.M. and Nørgaard, J.P. (2012) Desmopressin orally disintegrating tablet effectively reduces nocturia: Results of a randomized, doubleblind, placebo-controlled trial. Neurourology and Urodynamics, 31, 441-447. doi:10.1002/nau.22243

[4] Juul, K.V., Klein, B.M., Sandstrom, R., Erichsen, L. and Nørgaard, J.P. (2011) Gender difference in antidiuretic response to desmopressin. American Journal of Physiology—Renal Physiology, 300, F1116-F1122. doi:10.1152/ajprenal.00741.2010

[5] Yamaguchi, O., Nishizawa, O., Juul, K.V. and Nørgaard, J.P. (2013) Gender difference in efficacy and dose response in Japanese patients with nocturia treated with four different doses of desmopressin orally disintegrating tablet in a randomized, placebo-controlled trial. BJU International, 111, 474-484. doi:10.1111/j.1464-410X.2012.11547.x

[6] Juul, K.V., Klein, B.M. and Nørgaard, J.P. (2012) Longterm durability of the response to desmopressin in female and male nocturia patients. Neurourology and Urodynamics, 32, 363-370. doi:10.1002/nau.22306

[7] Rittig, S., Knudsen, U.B., Nørgaard, J.P., Pedersen, E.B. and Djurhuus, J.C. (1989) Abnormal diurnal rhythm of plasma vasopressin and urinary output in patients with enuresis. American Journal of Physiology, 256, F664-F671.

[8] Yeung, C.K., Sreedhar, B., Sihoe, J.D., Sit, F.K. and Lau, J. (2006) Differences in characteristics of nocturnal enuresis between children and adolescents: A critical appraisal from a large epidemiological study. BJU International, 97, 1069-1073. doi:10.1111/j.1464-410X.2006.06074.X

[9] Rittig, S., Schaumburg, H.L., Siggaard, C., Schmidt, F. and Djurhuus, J.C. (2008) The circadian defect in plasma 
vasopressin and urine output is related to desmopressin response and enuresis status in children with nocturnal enuresis. The Journal of Urology, 179, 2389-2395. doi:10.1016/j.juro.2008.01.171

[10] Hancock, M.L., Bichet, D.G., Eckert, G.J., Bankir, L., Wagner M.A. and Pratt, J.H. (2010) Race, sex, and the regulation of urine osmolality: Observations made during water deprivation. American Journal Physiology-Regulatory Integrative and Comparative Physiology, 299, R977R980. doi:10.1152/ajpregu.00289.2010

[11] Hvistendahl, G.M., Riis, A., Nørgaard, J.P. and Djurhuus, J.C. (2005) The pharmacokinetics of 400 microg of oral desmopressin in elderly patients with nocturia, and the correlation between the absorption of desmopressin and clinical effect. BJU International, 95, 804-809. doi:10.1111/j.1464-410X.2005.05405.X

[12] Stachenfeld, N.S., Gleim, G.W., Zabetakis, P.M. and Nicholas, J.A. (1996) Fluid balance and renal response following dehydrating exercise in well-trained men and women. European Journal of Applied Physiology and Occupational Physiology, 72, 468-477. doi:10.1007/BF00242277

[13] Weiss, J.P., Bosch, J.L., Drake, M., Dmochowski, R.R., Hashim, H., Hijaz, A., Johnson, T.M., Juul, K.V., Nørgaard, J.P., Norton, P., Robinson, D., Tikkinen, K.A., van Kerrebroeck, P.E. and Wein, A.J. (2012) Nocturia think tank: Focus on nocturnal polyuria: ICI-RS 2011. Neurourology and Urodynamics, 31, 330-339. doi:10.1002/nau.22219

[14] Vande Walle, J.G., Bogaert, G.A., Mattsson, S., Schurmans, T., Hoebeke, P., Deboe, V. and Nørgaard, J.P. (2006) A new fast-melting oral formulation of desmopressin: A pharmacodynamic study in children with primary nocturnal enuresis. BJU International, 97, 603-609. doi:10.1111/j.1464-410X.2006.05999.x

[15] Osterberg, O., Savic, R.M., Karlsson, M.O., Simonsson, U.S., Nørgaard, J.P., Vande Walle, J. and Agersø, H. (2006) Pharmacokinetics of desmopressin administrated as an oral lyophilisate dosage form in children with primary nocturnal enuresis and healthy adults. The Journal of Clinical Pharmacology, 46, 1204-1211. doi:10.1177/0091270006291838

[16] Wang, Y.X., Crofton, J.T., Liu, H., Brooks, D.P. and Share, L. (1994) Effects of gonadectomy on sexually dimorphic antidiuretic action of vasopressin in conscious rats. American Journal of Physiology-Regulatory, Integrative and Comparative Physiology, 267, R536-R541.

[17] Wang, Y.X., Crofton, J.T., Miller, J., Sigman, C.J., Liu, H., Huber, J.M., Brooks, D.P. and Share, L. (1996) Sex difference in urinary concentrating ability of rats with water deprivation. American Journal of Physiology-Regulatory, Integrative and Comparative Physiology, 270, R550-R555.

[18] Wang, Y.X., Crofton, J.T. and Share, L. (1997) Sex differences in the cardiovascular and renal actions of vasopressin in conscious rats. American Journal of Physiology—Regulatory, Integrative and Comparative Physiology, 272, R370-R376.

[19] Wang, Y.X., Edwards, R.M., Nambi, P., Stack, E.J., Pullen, M., Share, L., Crofton, J.T. and Brooks, D.P.
(1993) Sex difference in the antidiuretic activity of vasopressin in the rat. American Journal of Physiology-Regulatory, Integrative and Comparitive Physiology, 265, R1284-R1290.

[20] Liu, J., Sharma, N., Zheng, W., Ji, H., Tam, H., Wu, X., Manigrasso, M.B., Sandberg, K. and Verbalis, J.G. (2011) Sex differences in vasopressin $\mathrm{V}(2)$ receptor expression and vasopressin-induced antidiuresis. American Journal of Physiology—Renal Physiology, 300, F433-F440. doi:10.1152/ajprenal.00199.2010

[21] Stachenfeld, N. and Keefe, D.L. (2002) Estrogen effects on osmotic regulation of AVP and fluid balance. American Journal of Physiology-Endocrinology and Metabolism, 283, E711-E721.

[22] Schoeftner, S., Blanco, R., Lopez de Silanes, I., Muñoz, P., Gómez-López, G., Flores, J.M. and Blasco, M.A. (2009) Telomere shortening relaxes X chromosome inactivation and forces global transcriptome alterations. Proceedings of the National Academy of Sciences of the United States of America, 106, 19393-19398. doi:10.1073/pnas.0909265106

[23] Yang, F., Babak, T., Shendure, J. and Disteche, C.M. (2010) Global survey of escape from $X$ inactivation by RNA-sequencing in mouse. Genome Research, 20, 614622. doi:10.1101/gr.103200.109

[24] Nørgaard, J.P., Pedersen, E.B. and Djurhuus, J.C. (1985) Diurnal anti-diuretic-hormone levels in enuretics. Journal of Urology, 134, 1029-1031.

[25] Gentilini, D., Castaldi, D., Mari, D., Monti, D., Franceschi, C., Di Blasio, A.M. and Vitale, G. (2012) Agedependent skewing of $\mathrm{X}$ chromosome inactivation appears delayed in centenarians' offspring. Is there a role for allelic imbalance in healthy aging and longevity? Aging Cell, 11, 277-283. doi:10.1111/j.1474-9726.2012.00790.x

[26] Migeon, B.R. (2008) X inactivation, female mosaicism, and sex differences in renal diseases. Journal of the American Society of Nephrology, 19, 2052-2059. doi:10.1681/ASN.2008020198

[27] Demura, M., Takeda, Y., Yoneda, T., Oda, N., Bando, Y. and Mabuchi, H. (2004) Surgical stress-induced transient nephrogenic diabetes insipidus (NDI) associated with decreased vasopressin receptor2 (AVPR2) expression linked to nonsense-mediated mRNA decay and incomplete skewed X-inactivation in a female patient with a heterozygous AVPR2 mutation (c. 89-90 delAC). Clinical Endocrinology, 60, 773-775. doi:10.1111/j.1365-2265.2004.02042.x

[28] Fjellestad-Paulsen, A., Wille, S. and Harris, A.S. (1987) Comparison of intranasal and oral desmopressin for nocturnal enuresis. Archives of Disease in Childhood, 62, 674-677. doi:10.1136/adc.62.7.674

[29] Odeberg, J.M., Callréus, T., Lundin, S., Roth, E.B. and Höglund, P. (2004) A pharmacokinetic and pharmacodynamic study of desmopressin: Evaluating sex differences and the effect of pre-treatment with piroxicam, and further validation of an indirect response model. Journal of Pharmacy and Pharmacology, 56, 1389-1398. doi:10.1211/0022357044535 